\title{
A Systemist 'Verb Transitivity' Analysis of the Persian and English Newspaper Editorials: A Focus of Genre Familiarity on EFL Learner's Reading Comprehension
}

\author{
Hossein Shokouhi \\ Shahid Chamran University of Ahvaz, Ahvaz, Iran \\ Email: shokouhi_hossein@yahoo.com \\ Forough Amin \\ Shahid Chamran University of Ahvaz, Ahvaz, Iran
}

\begin{abstract}
The aim of this study is two-fold: 1) to identify the editorials of six English and Persian newspapers (two native English, two native Farsi and two English written by non-natives) in terms of generic structures and 2) investigate the role that each generic factor (structure, content, and context) plays in the comprehension of a particular genre. At the first stage of the study 90 samples of six English and Persian newspapers were collected and analyzed using Systemic Functional approach to language analysis. Then, four texts from the English samples (two written by American native writers and two by Iranian non-native writers of English) were administered to 27 EFL students of Shahid Chamran University to answer a number of questions regarding structure, content, and context of the texts. Analysis of the samples revealed that the editorials of all six newspapers had similar generic structure- consisting of three obligatory and three optional categoriesregardless of language or place of publication. Moreover, results of the four reading comprehension tests showed that differences in students' performance was due to their various degrees of familiarity with content and context, and not the structure of the texts.
\end{abstract}

Index Terms - systemic, Persian, English, newspaper, reading comprehension, EFL

\section{INTRODUCTION}

There has been a renewed interest in the concept of genre in several disciplines such as education, applied linguistics, pragmatics, and TEFL. Genre analysis has become a popular framework for investigating the form and function of both oral and written discourse; it also serves as a tool for developing educational practices in the field of language teaching. Genre-based approach in contrast to many other approaches like schema approach is multi-dimensional and works on different aspects of a genre- form, function, content, and context (purpose, reader/writer, etc.).

Along with this, reading comprehension research in the last two decades has focused on two major issues among others: the reader's prior knowledge, and the notion of reader as an active subject whose mental background interacts with the texts. The role of background knowledge in process of reading comprehension has been studied by schema theorists, concentrating on formal and content schema. A formal schema is understood as representing the knowledge that the reader has about formal characteristics of texts, especially their structures or sequences (e.g. cause-effect, problem-solution, etc.), and their functions (expository, descriptive, argumentative, etc.). Content schema, on the other hand, deals with reader's prior knowledge about topics covered in the texts.

In spite of the growing attention paid to the role of genre familiarity in reading and writing processes, applying this approach in educational settings has been limited to teaching formal structures of genres whereas genre knowledge includes not only awareness of genre formal features but also communicative purposes, reader/ writer roles, content and contextual structures. Such an approach in teaching reading, which focuses on genre formal features, is similar to the schema-based approaches. The chief difference is that in the former, structure of a particular genre is identified and taught to the students but in the latter, the focus is on text-types (cause-effect, problem-solution, comparison-contrast, etc.).

According to Toledo (2005: 1061), the concept of genre implies the consideration of socio-cultural conventions that exist around texts when measuring readers' comprehension of a text. Without being aware of the readers' knowledge of contextual dimension that constrain a text at different levels, we cannot determine whether or not they have understood the text massage. Considering this, we decided to conduct a study which included the notion of genre in testing reading comprehension and measuring readers' schema. This study was then conducted to determine the role of generic structure, content, and context in reading comprehension of a specific genre, that is, newspaper editorial and to see if 
genre content and context are as important as genre structure in understanding a text.

\section{BACKGROUND}

\section{A. An Introduction to CC and GSP}

The term 'Contextual Configuration' or CC was introduced by Halliday and Hasan (1989) as a specific set of values that realizes field, tenor, and mode. Each of these variables functions as an entry to any situation as a set of possibilities and/or options. Thus, the variable 'Field' may have the value 'praising' or 'blaming'; 'Tenor' may allow a choice between 'parent-to-child' or 'employer-to-employee while 'Mode' might be 'speech' or 'writing' (Halliday, 1994). Any member of related pair of options can combine with any other member to form a specific CC.

Moreover, linking this approach to text analysis, Halliday and Hasan (1989: 63-65) introduced the concept of 'Generic Structure Potential (GSP)' for any specific CCs to define a genre. For example, in order to identify the obligatory and optional rhetorical elements of 'Service Encounter' texts, they examined a set of similar spoken texts in this regard and established the GSP of the 'Shop Transaction' genre as follows:

$\left[(\mathrm{G}) .(\mathrm{SI})^{\wedge}\right]\left[(\mathrm{SE}).\left\{\mathrm{SR}^{\wedge} \mathrm{SC}^{\wedge}\right\}{ }^{\wedge} \mathrm{S}^{\wedge}\right] \mathrm{P}^{\wedge} \mathrm{PC}\left({ }^{\wedge} \mathrm{F}\right)$

Specifically, GSP represents the conditions under which a text is appropriate to a CC. In simple words, any shop transaction in English potentially consists of the following macro-structural elements: Greeting (G), followed by Sale Initiation (SI), Sale Enquiry (SE), Sale Request (SR), Sale Compliance (SC), Sale (S), Purchase (P), Purchase Closure (PC), and Finish (F). The round brackets in the above GSP indicate optionality of the enclosed elements. Therefore, G, SI, SE, and F are optional and SR, SC, S, P, and PC are obligatory. The dot between elements indicates 'more than one' option in sequence, and the arrow shows iteration. The braces with a curved arrow manifest the degree of iteration equality of elements in the square brackets. That is to say, if SR occurs twice, then SC must also occur twice. Finally, the caret $\operatorname{sign}\left({ }^{\wedge}\right)$ shows sequence.

While optional elements do not occur randomly, their optionality arises from the fact that their occurrence is predicted by some attribute of CC that is non-defining for the CC. Therefore, it is not surprising that optional elements have wider applicability. For example, in genre of shop transaction, the element Sale Initiation (who's next?) can act as the initiating element of many other service encounters. An obligatory element is one in the absence of which the text would not be interpreted as the genre to which the text belongs. Such elements can vary in size, but normally contain at least one proposition.

\section{B. Analysis of Newspaper Genre}

In a study to explore the distinctive rhetorical features of English newspaper editorials, Ansary and Babaii (2004) applied Hallidayian approach to propose a generic pattern of text development for editorials. They collected 30 editorials from 'Washington Times' as representative of the American newspapers. They found four obligatory elements (Run-on Headline, Addressing an Issue, Argumentation, and Articulating a Position) present in the $90 \%$ of the editorials in the sample. Optional elements in the editorials were providing Background Information (BI), which either preceded Addressing an Issue (AI) or followed it, Initiation of Argumentation (IA) which, in some cases, was necessary to help writers start off their arguments, and Closure of Argumentation (CA) which sometimes used to round off the arguments.

O'Donnell (2006) conducted a contrastive study between the registers of two newspaper text-types: front page news and editorials to explore how these text-types differ in the way they use grammatical tense. For this study, a corpus of newspaper articles was collected from six American and one British newspapers. He considered the grammatical tense in terms of the semantic concept of the realis function. Realis concerns the actual occurrence of an event or state. A realis process is one which has either actually occurred or is still in the process of occurring. All other processes are labeled irrealis- processes which have not happened, and not happening now. Grammatical tenses of past (simple, perfect, continuous), and present (simple, perfect, continuous) are considered as realis. On the other hand, future tense, modals and denials are considered irrealis. The result of this study revealed that in the front page news, realis were used more than irrealis whereas more irrealis were adopted in the editorial section. The difference indicates that front page news mostly report the occurred event while editorial discusses the events which could have occurred in past or may occur in future, or the possible results of these events.

Katajamaki and Koskelain (2007) studied the rhetorical structure of editorials in English, Swedish and Finnish business newspapers: Financial Times, Dagens Industri, and Taloussanomat. They sought to answer the following questions: first, if there was a typical rhetorical structure for the editorials in business newspapers irrespective of national and cultural features; second, if there were different types; and third, what factors were connected to the content of the text, language and culture which would correlate with the different types. The material of the study consisted of 22 editorials from these three business newspapers. As a starting point for their analysis, they used a modification of Van Dijk's (1993) view of the rhetorical structure of editorials. Van Dijk (1993) quoted in Katajamaki and Koskelain (2007: 2) divides editorials into three sections each having specific stage(s) and function. The stages are the introductory section, the intermediate section which in turn is divided into a) the reason section, evidence or examples, and b) the solution section, and the coda section which is the closing section.

The rhetorical structure of the material showed little variation in spite of the fact that the texts represent three countries and three languages. 


\section{METHOD}

\section{A. Questions}

This study was designed to answer the following questions:

1. What are the GSP of English and Persian editorials in the following newspapers; Keyhan, Resalat, Tehran Times, Kayhan International, New York Times, and Washington Times as portrayed in Systemic Functional Linguistic model?

2. Are English-language newspapers published in Iran influenced by the rhetorical structure used in the native newspapers?

3. Is it possible to claim that Iranian students' (un)familiarity with the editorial section of the newspaper genre affect their comprehension of editorials in English?

4. Which of the generic factors (structure, content, and context) has larger effect on reading comprehension?

\section{B. Materials and Participants}

The data for this study were collected from six newspapers: Keyhan and Resalat as representatives of Persian newspapers, Tehran Times and Keyhan international written in English in Iran, and New York Times and Washington Times representatives of newspapers published in America. On the whole, 15 samples from each newspaper which comprised a total of 90 samples published in the year 2008 were gathered. The samples were collected in a relatively long period of three months from January to March in order to have a corpus of texts written about various topics. In order to see the variety, one third of the samples were gathered from the beginning of the week, one third from the midweek, and the other from the weekend. The aim, as stated above, was to gather data on a variety of topics on weekdays and weekends, so that the probability of writing variation due to the variation of topics could be checked and the pattern derived as a result of analyzing these editorials can be a comprehensive model for writing editorial.

As regards the participants, there were 27 Persian EFL students who studied English at Shahid Chamran University of Ahvaz. The subjects were the third year students who had passed three reading comprehension courses and one course on 'Reading the Press'.

\section{Procedure}

Following Halliday and Hasan (1989), Ghadessy (1993), Paltridge (1993) Henry and Roseberry (1997), Ansary (2004), Ansary and Babaii (2004) and Hodges (2006), among others, have adopted their model. In the first stage in this model, the macro-rhetorical structure (GSP) of the editorials as a sub-genre of the newspaper genre was to be identified. In addition, we had to check the process, tense and meta-textual signal variations in all the 90 texts. The aim was to find out whether there was any correspondence between linguistic variations in the texts and functions of the editorial elements identified in the texts.

In the second stage of the study (the reading comprehension phase), four texts from the English editorials (two from Tehran Times and Keyhan International, and two from New York Times and Washington Times) followed by a series of multiple choice and open-ended questions were administered to the subjects. The readability level of the texts was computed to be in range of 11 to 12 , which shows that the difficulty level of these texts was similar.

\section{RESULTS}

\section{A. GSP of Newspaper Editorials}

In order to find out the GSP of the editorials of the six newspapers, fifteen samples of each were analyzed separately. Analysis of the samples revealed a consistent structural pattern within and across the newspapers. This overall pattern consisted of six obligatory and optional elements which will be discussed below. The writers' explicit text division devices (paragraph divisions, italics, underlining, order of presentation, and other typographical devices) in addition to linguistic elements such as connectors and meta-textual signals (e.g. however, consequently, in summary, in contrary, on the whole, etc), tense and process changes (e.g. present/past tenses, material/relational processes), introduction of new lexical references and evaluative lexis such as negative/positive adjectives and adverbs were helpful cues in identification of the obligatory and optional elements.

\section{B. Obligatory Elements}

Three of the six structural elements found in the editorial texts were obligatory, that is Headline, Addressing an Issue and Argumentation. This means all the 90 sample texts included these three. The appearance of these elements in a specific order corresponds to our perception of whether the text is complete or incomplete (Halliday and Hasan, 1989: 62).

\section{Headline $(\mathbf{H})$}

The first element identified in the sample editorials was the title of the article called Headline. It establishes a theme around which the editorial is centered. In this study, Headline as an obligatory element was found in all the ninety samples we surveyed, yielding a frequency of $100 \%$.

\section{Addressing an issue (AI)}

The AI serves as a motivation for the editorial. In other words, it indicates that there exists an issue which must be 
debated. The issue is often an important current socio-political topic that must necessarily be discussed and is sometimes resolved. This is the second obligatory element in an editorial whose position depends on the presence as well as the position of an optional element called Providing Background Information (see below). If the editorial includes the optional element of providing background information, AI may precede or follow it.

\section{Argumentation (A)}

This category refers to both the process of argumentation and the arguments produced in that process. Argumentation uses linguistic cues to justify or refute a standpoint, with the aim of securing views in agreement. Specifically, propositions are put forward as claims (made by the writer or others) and, sometimes, evidence or reasons are presented as justification and/or refutation of those claims. Argumentation process itself includes two optional sub-elements: Initiation of Argumentation (IA) which, in some cases, is necessary to help writers start off their arguments, and Closure of Argumentation (CA) sometimes used to nicely round off the arguments. Argumentation is the third obligatory category of the editorial and tends to appear after AI and the optional element of the background information (BI). Frequency of $\mathrm{A}$ in this study was $100 \%$ which indicates that all the texts possessed the feature. Following is what we depicted for the overall patter of the texts: $\mathrm{H}^{\wedge}\left[(\mathrm{BI} .)^{\wedge} \mathrm{AI}\right]^{\wedge} \mathrm{A}$.

\section{Optional elements}

The other categories making up the GSP of the editorials are three optional ones. An optional element is one that can occur but is not obliged to occur and the condition under which there is a high probability of its occurrence is explainable (Ibid). The optional elements of our sample texts were Providing Background Information (BI), Articulating a Solution (AS), and Concluding Remarks (CR). They are considered as optional because they were found in only some of the samples and under specific conditions.

1) Providing background information (BI)

BI makes reference to a place, thing, or situation some aspects of which are addressed below. Most of the time, this category is in form of news which appears before or after the obligatory element of AI. BI is the rhetorical device which gives readers some background on the major issue(s) that are addressed in the text. It is essentially a description whose purpose is to set the scene for later development of the topic.

2) Articulating a solution (AS)

This category specifies the writer's solution for the debated problem and how it can be resolved. AS has two positions in the editorials; sometimes, it comes at the beginning of an editorial in which case it follows the AI, and sometimes, it appears at the very end of it. AS was found in the editorials whose task was not only to discuss an issue but also suggest a solution for a problem.

3) Concluding remarks (CR)

Conclusion which summarizes the whole article is the last category that may be found in an editorial. Presence of CR in an editorial is usually dependent of whether AS comes at the beginning or end of an article. If AS appears finally, it acts as a conclusion and wraps up the editorial, so no conclusion is necessary. But in situations where AS appears initially or does not occur at all, the text requires a conclusion.

In general, the GSP of these editorial texts can be shown as follows:

$\mathrm{H}^{\wedge}\left[(\mathrm{BI}){ }^{\wedge} \mathrm{AI}\right]^{\wedge}[\mathrm{A} \wedge$ ( $\left.\mathrm{AS}).\right]^{\wedge}(\mathrm{CR})$

The round brackets in the above GSP indicate optionality of the enclosed elements. Therefore BI, AS and CR are optional and H, AI, A are obligatory. The dot indicates more than one option in the sequence. However, optionality of sequence is never equal to complete freedom; the restraint is indicated by the square bracket. For example, if BI occurs as an optional element, it may precede or follow AI. It cannot follow or precede the elements out of the square brackets. The same holds true for AS in the following brackets. The caret sign $(\wedge)$ shows the sequence. Violation of sequence in a section can bring disorder to that section of a text, hence hard to follow.

\section{Lexico-grammatical Manifestations of Structural Elements}

Lexico-grammatical variations such as changes in processes and tenses are useful cues in identification of GSPs of the genres. In this study, these variations in the editorial texts were surveyed in order to see whether the lexicogrammatical changes correspond to the functional obligatory and optional categories identified in the editorials.

\section{Process variation}

Transitivity system that we adopted includes six types of processes; namely, material, relational, verbal, behavioral, mental, and existential. Frequencies of these six types of processes in each editorial element were calculated for all the ninety texts, which revealed that among all the processes, three of them (Material, Relational, and Mental) were used more than the other three in the structural elements of the editorials (see tables below). 
TABLE 1.

PROCESS VARIATION AMONG DIFFERENT ELEMENTS OF THE SIX NEWSPAPERS

\begin{tabular}{|c|c|c|c|c|}
\hline & Material Process & Relational Process & Mental Process & $\begin{array}{c}\text { Total No. of } \\
\text { Processes }\end{array}$ \\
\hline Addressing issue & $290(54 \%)$ & $186(31 \%)$ & $103(15 \%)$ & 579 \\
\hline $\begin{array}{c}\text { Background } \\
\text { information }\end{array}$ & $154(55 \%)$ & $84(30 \%)$ & $42(15 \%)$ & 278 \\
\hline Argumentation & $450(47 \%)$ & $278(27 \%)$ & $269(26 \%)$ & 997 \\
\hline $\begin{array}{c}\text { Articulating a } \\
\text { solution }\end{array}$ & $69(36 \%)$ & $75(40 \%)$ & $45(24 \%)$ & 189 \\
\hline
\end{tabular}

As Table 1 indicates, there are variations in the use of processes in different parts of the editorials. Material process and following that relational process are used more than the mental process in AI and BI. In A, material process is again the dominant process but here relational $(27 \%)$ and mental $(26 \%)$ processes have similar percentage of occurrence. In AS, the situation is different- it is the relational process which has been largely used (40\%) and after that the material process $(36 \%)$ and the difference between the two is not considerable. Although mental process has been used less than the other two processes (material and relational) in all the elements, its occurrence in elements A (26\%) and AS (24\%) is more than $\mathrm{AI}(15 \%)$ and $\mathrm{BI}(15 \%)$. In A, the mental process $(26 \%)$ has a percentage close to the relational process $(27 \%)$ and both A $(26 \%)$ and AS $(24 \%)$ have similar percentages of mental process.

These differences are indicators of the roles they play in the editorial. Primary roles of AI and BI are to report the events which occurred in the past (BI) or are occurring now (AI), so the use of material process is more than other processes in these elements. In A the writer comments not only about what occurred or is occurring (material process) but also about positive or negative effects of those events (relational process) as well as what s/he and others think should or could have occurred (mental process). In AS, the writer presents his/her ideas (mental process) about what should be done (material process) or how the situation/people should be treated (relational process) in order to resolve a problem.

\section{Tense variation}

A significant grammatical variation in the editorial texts is variation of tenses. According to O' Donnell (2006: 2), the grammatical tense can be considered in terms of the semantic concept of realis. This concept, which itself is divided into realis and irrealis, is concerned with the verb use. Grammatical tenses of past and present (simple, perfect, continuous) are considered as realis. On the other hand, future tense, modals and denials are irrealis.

TABLE 2.

FREQUENCIES AND PERCENTAGES OF REALIS IN ELEMETS OF ALL SIX NEWSPAPERS

\begin{tabular}{|c|c|c|c|}
\hline & $\begin{array}{c}\text { Present (simple, perfect, \& } \\
\text { continuous) }\end{array}$ & $\begin{array}{c}\text { Past (simple, perfect, \& } \\
\text { continuous) }\end{array}$ & Total No. of Tenses \\
\hline Addressing issue & $302(64 \%)$ & $175(36 \%)$ & $477(88 \%)$ \\
\hline Background information & $61(28 \%)$ & $157(72 \%)$ & $219(87 \%)$ \\
\hline Argumentation & $434(53 \%)$ & $385(47 \%)$ & $819(60 \%)$ \\
\hline Articulating solution & $113(83 \%)$ & $22(17 \%)$ & $135(49 \%)$ \\
\hline
\end{tabular}

TABLE 3

FREQUENCIES AND PERCENTAGES OF IRREALIS IN ELEMETS OF ALL SIX NEWSPAPERS

\begin{tabular}{|c|c|c|c|c|}
\hline & Present Modals & Past Modals & Future Modals & Total No. of Modals \\
\hline Addressing issue & $25(48 \%)$ & $18(35 \%)$ & $9(17 \%)$ & $52(12 \%)$ \\
\hline Background information & $12(39 \%)$ & $12(39 \%)$ & $7(22 \%)$ & $31(13 \%)$ \\
\hline Argumentation & $177(54 \%)$ & $114(35 \%)$ & $36(11 \%)$ & $327(40 \%)$ \\
\hline Articulating a solution & $39(56 \%)$ & $14(20 \%)$ & $17(24 \%)$ & $70(51 \%)$ \\
\hline
\end{tabular}

According to Table 2, in AI and AS, present is the dominant tense (64\% and $83 \%$ respectively) but in case of BI, it is the reverse- past tense $(72 \%)$ has been used more than present tense $(28 \%)$. In A, present and past tenses have similar percentages of occurrence (53\% and 47\%). Considering irrealis (Table 3), use of modals in AI and BI is limited (12\% and $13 \%$ ) but in A and AS, the occurrence of modals is about fifty percent. In terms of realis and irrealis, AI and BI have used realis $(88 \%$ and $87 \%$ ) much more than irrealis (12\% and $13 \%$ respectively). Nevertheless, the difference between the occurrence of realis (60\%) and irrealis (40\%) in A is not as much as AI and BI, and in AS the occurrence of irrealis (51\%) is slightly more than realis (49\%). Another interesting point is the difference in types of modals used in A and AS. Modals used in A were those indicating possibility or ability (may, might, can, could) but those found in AS showed obligation or recommendation (must, should, ought to). Variation in the use of more realis than irrealis in AI and $\mathrm{BI}$ is because is because these two present real events (what happened or is happening); besides, BI uses past tense more than present because its role is to narrate the occurred events. A uses similar proportions of present, past, and modals since its function is to discuss what happened (past tense) or should or might have happened (modals) in the past and their possible consequences for present (present tense) and future (modals). More use of present tense and modals in AS refers to the fact AS suggests what should be done now (modals and present) in order to achieve some 
possible goals in future (modals).

\section{Reading Comprehension Test}

After identification of GSP of the texts, four reading comprehension tests were administered to 27 junior students studying English at Shahid Chamran University. The editorials used in Tests 1 and 3 were written by American newsmen and those used in Tests 2 and 4 were written by Iranians. The aim was to determine whether there was any difference in subjects' understanding of the editorials (written by native and non-native writers) resulted from variations of GSPs of the texts. To clarify that point, first, students' mean score for each of the four tests was calculated. Then we applied Pair T-test to find out if the differences between mean scores of the four tests were significant. These statistical analyses are presented below.

TABLE 4.

PAIRED T-TEST ANALYSIS OF THE FOUR TESTS

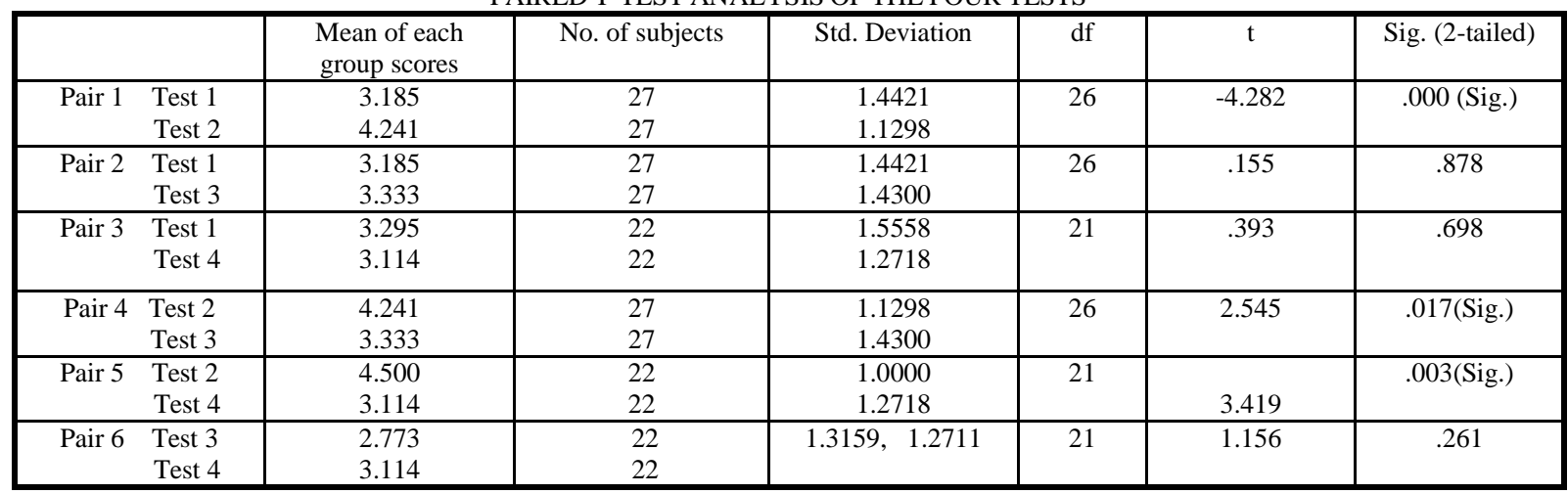

These statistics indicate a significant difference at 0.05 level between mean scores of test two (4.241) and other three tests (Table 11). It reveals that except for test two that students had a good performance on reading comprehension task, in tests one (3.185), three (3.333), and four (3.114) students' performance was at a similar low level.

\section{E. Correlation of Test Score and Text Structure}

One of the issues addressed in relation to the second phase of this study was the relationship between students' test scores and their comprehension of text structure (GSP). In order to clarify this, the correlation between these two factors, in each test, was calculated according to Pearson coefficient correlation.

TABLE 5 .

PEARSON CORRELATION FOR TEST 1

\begin{tabular}{|c|c|c|}
\hline & $\begin{array}{c}\text { Students' scores } \\
\text { on test 1 }\end{array}$ & $\begin{array}{c}\text { Students' } \\
\text { comprehension of } \\
\text { structure of text 1 }\end{array}$ \\
\hline Test 1 & 1 & $.481^{*}$ \\
Sig. (2-tailed) & 011 \\
N & 27 & 27 \\
\hline Structure comprehension 1 & $.481^{*}$ & 1 \\
Sig. (2-tailed) & .011 & 27 \\
N & 27 & \\
\hline
\end{tabular}

*Correlation is significant at the 0.05

TABLE 6.

PEARSON CORRELATION FOR TEST 2

\begin{tabular}{|c|c|c|}
\hline & $\begin{array}{c}\text { Students' scores } \\
\text { on test 2 }\end{array}$ & $\begin{array}{c}\text { Students' } \\
\text { comprehension of } \\
\text { structure of text 2 }\end{array}$ \\
\hline Test 2 & 1 & $.677^{* *}$ \\
Sig. (2-tailed) & 000 \\
N & 27 & 27 \\
\hline Structure comprehension 2 & $.677^{* *}$ & 1 \\
Sig. (2-tailed) & .000 & 27 \\
N & 27 & 27 \\
\hline
\end{tabular}

**Correlation is significant at the $0.01 \mathrm{le}$ 
TABLE 7.

PEARSON CORRELATION FOR TEST 3

\begin{tabular}{|c|c|c|}
\hline & $\begin{array}{c}\text { Students' scores } \\
\text { on test 3 }\end{array}$ & $\begin{array}{c}\text { Students' } \\
\text { comprehension of } \\
\text { structure of text 3 }\end{array}$ \\
\hline Test 3 & 1 & $.571^{* * *}$ \\
Sig. (2-tailed) & 27 & 27 \\
$\mathrm{~N}$ & $.571^{* *}$ & 1 \\
\hline Structure comprehension 3 & .002 & 27 \\
Sig. (2-tailed) & 27 & 27 \\
$\mathrm{~N}$ &
\end{tabular}

**Correlation is significant at the 0.01 le

TABLE 8.

PEARSON CORRELATION FOR TEST 4

\begin{tabular}{|c|c|c|}
\hline & $\begin{array}{c}\text { Students' scores } \\
\text { on test 4 }\end{array}$ & $\begin{array}{c}\text { Students' } \\
\text { comprehension of } \\
\text { structure of text 4 }\end{array}$ \\
\hline Test 4 & 1 & .281 \\
Sig. (2-tailed) & 22 & .205 \\
$\mathrm{~N}$ & .221 & 22 \\
\hline Structure comprehension 4 & .205 & 1 \\
Sig. (2-tailed) & 22 & 22 \\
$\mathrm{~N}$ & & \\
\hline
\end{tabular}

According to the analysis presented in the tables above, in all the tests except test 4 , there were positive correlations between test scores and students' comprehension of GSPs of the texts. This means in these three tests, those students who had comprehended the text structure properly were more successful in overall text comprehension and gained higher scores in the tests.

\section{DISCUSSION}

Results of the study can be discussed in two parts: differences in GSP of the editorials and differences in the students' performance on reading comprehension tests. Significant differences in these two parts are discussed below.

\section{A. Variations in Actual GSPs}

Although all the editorials in this study belong to one GSP, the actual realization of this in each editorial is different (variations are due to the optional elements). In this regard, the editorials can be categorized into two groups: those which contain the element 'AS' and those which do not. The editorials which do not include this element, that is editorials written to discuss some views without resolving a problem, contain the element ' $\mathrm{CR}$ ' at the end to summarize the article. However, the editorials which contain the element 'AS' may or may not have the element 'CR'. Here two situations can be assumed; if the element ' $\mathrm{AS}$ ' comes at the beginning of the editorial, there should be a ' $\mathrm{CR}$ ' in order to round off the article. However, If 'AS' comes at the end of the editorial, it acts as a conclusion and there is no need for the element ' $C R$ '.

As for the classification of obligatory and optional elements, the results of the present study are not consistent with Ansary and Babai (2004) on Washington Times newspaper editorials. They identified an obligatory element which they called Articulating a Position. However, in this study instead of that obligatory element, there is an optional element called Articulating a Solution which is in fact part of what Ansary and Babai named Articulating a Position. They assumed that the writer of the editorial first presents an issue, then in the process of Argumentation, discusses different views about the issue, and finally suggests his/her own idea. However, this study showed that in nearly all samples (included samples from Washington Times), from the beginning to the end of Argumentation, the writer presents not only different opposing ideas but also his/her own ideas.

Each argument produced in Argumentation process includes the writer's ideas and in some cases the opposing ideas. It was found that no specific section apart from Argumentation can be considered for Articulating a position. In fact, Argumentation is a process of Claim + Reason; the writer presents the claims which are contrary to his/her ideas and sometimes the reasons provided for those claims, then challenges those claims and the reasons to discard them and proves his/her own ideas. Therefore, in each step of Argumentation process, the writer presents his/her position regarding the issue.

On the whole, in each editorial, there are two groups of ideas; the writer's idea and those which are often contrary to the writer's opinion. Therefore, what Ansary and Babai (2004) named Articulating a Position is often a part of Argumentation section. Moreover, it is sometimes Articulating a Solution which can be found as an optional element in the editorials which are written to suggest solutions for a problematic issue.

Greater use of modals (should, must, ought to, etc.) as well as relational and mental processes in the element of Articulating a Solution shows that what is presented here is not just a narration of events (like BI and AI) or an opinion 
(like A) but a solution (a suggestion which should be carried out in order to resolve a problem). Another difference between elements found in this study and one conducted by Ansary and Babai (2004) is that no attempt was made to identify CR in the editorials. According to what is reported in that study, the last element of the editorial is the obligatory element of Articulating a Position. On the contrary, we could identify CR as an optional category which was found in 67 of the 90 samples and under specific conditions. This came at the end of the editorial and occurred in two situations- when the editorial did not include AS or when AS appeared at the beginning of the editorial.

Our findings regarding the difference between AS and A with AI and BI in the use of grammatical tenses are like O'Donnell's (2006) findings in a contrastive study on editorials and front page news. He (2006: 5) found that in front page news, realis past $(61 \%)$ and present $(16 \%)$ were used more than future, modals, and denials called irrealis $(23 \%)$, but in the editorials both realis and irrealis had the same percentage of occurrence (50\%). The same is true with AI, BI, A, and AS in our study- in AS and A, the use of realis (49\% and 60\%) and irrealis (51\% and 40\%) is, to some extent, similar to each other but in $\mathrm{AI}$ and $\mathrm{BI}$, it is $(88 \%$ and $87 \%)$ far more than irrealis (12\% and $13 \%$ respectively). The reason stated by O'Donnell (2006: 5) for the difference between front page news and editorials in the use of grammatical tenses which can also be applicable to this study in terms of variation among structural elements of the editorial is that different functions of these two registers- front page news (which in our case resembles elements AI and $\mathrm{BI}$ ) necessitates reporting the events that have occurred or are occurring, and editorials (similar to our A and AS paradigms) discuss the events that could or should have occurred in past, may or must occur now, and/or the possible consequences of those events in future.

Considering the study conducted by Katajamaki and Koskelain (2007), results of our study are consistent with their findings on the rhetorical structure of editorials in English, Swedish, and Finish business newspapers. Their study approved the model presented by Van Dijk (1993 cited in Katajamaki and Koskelain, 2007: 216) for rhetorical structure of editorials. The model consisted of three sections: introduction, intermediate section (analysis of event and solution), and coda. The rhetorical structure of their material like ours revealed little variation across countries and languages. They found that rhetorical structure of business editorials is like that of editorials in general newspapers and concluded that the editorial is a rather unified genre irrespective of the type of journalism in which it occurs.

Moreover, this study confirms the results of Ansary (2004) on samples collected from Washington Times and two non-native Pakistan Today and Iran News English editorials. Ansary's (2004) study, like ours, revealed that in terms of rhetorical structures, there is statistically no significant difference between English newspaper editorials written by native editorial writers and those written by non-native writers in whatever socio-cultural and socio-political context they are produced.

However, our study showed that the socio-political context in which a text is produced has a great influence on the content of that text. For example in case of our samples, editorials written by Americans were representatives of Westernist positions toward international issues (Palestine/Israel struggles, Iraq occupation, Iran's nuclear program, etc.) and those written by Iranians conveyed the same ideas presented by Iranian administration and officials.

\section{B. Variations in Students' Test Performance}

Considering the hypotheses presented in this study, the results of both parts of the study (Generic structures and reading comprehension tests) proved the null hypothesis which claims that all the six newspapers- Keyhan, Resalat, Tehran Times, Iran Daily, New York Times, and Washington Times- have similar obligatory GSPs and the differences in students' performances on reading comprehension tests result from their (un)familiarity with content and context not structure of the texts.

However, the variations that we witnessed in the earlier sections in case of text structures were due to the presence and position of the optional elements. Moreover, the differences found in students' performance on reading tests had resulted from generic factors (familiarity with content and context of the texts) other than text structures.

As the result shows, the students' best performance is in test two (mean: 4.24). In the other three tests (tests 1, 3, and 4), Pair t-test showed that there was no significant difference in the subjects' performance (mean of test one: 3.18 , test three: 3.33 and test four: 3.11). This difference between their performance on test 2 and the other three can neither be attributed to the GSPs of the editorials nor to their difficulty levels because as our analysis showed all the text shared similar GSP or generic structure consisting of three obligatory and three optional categories- $\mathrm{H}^{\wedge}\left[(\mathrm{BI}) .^{\wedge} \mathrm{AI}\right]{ }^{\wedge}\left[\mathrm{A} \wedge^{\wedge}\right.$ $(\mathrm{AS}).]^{\wedge}(\mathrm{CR})$ - and according to Fog's readability formula, texts used in reading comprehension tests had similar difficulty levels (range from11 to12). The differences, however, on the four tests can be discussed from two standpoints; content/context effect and structure effect.

\section{Content and context effect}

It seems that the subjects' content schema has played an important role in their comprehension of the texts. Although all the texts were political, they were about different issues. The first one was about 'Bush's State of Union address', the second about 'Arab peace plan for Palestine', the third 'U.S policy in Iraq', and the fourth 'U.S. terrorist actions in Iraq'. Students' degree of familiarity with these topics was not the same. Texts 1 and 3 were about U.S. policy and the relations between parties, congress, and government (written by an American) so it is not surprising that students did not have enough background knowledge in the field. Text 4 was about Iraq situation and particular persons, groups, and events in that country. This text also contained some information which was too detailed for the subjects.

As the students' answer to the questions- how much do you read/listen to the news? or how much do you read 
editorials?- showed, the subjects did not have so much familiarity with political issues. In fact, they had only a general knowledge about political events. So it is clear why they had better performance on test 2. This text discussed the general issue of "Palestine and Israel struggles", and "Arab countries' plan for peace"- a topic which is daily portrayed on different Iranian media. If the text were about a specific event in that country such as a movement of Palestinian Jihadist groups, or a decision made by Israeli government, students' performance was not as good.

The study also showed that recognition of the context in which each the text was produced (Iran and U.S.) had a positive impact on the comprehension of the content. The subjects, who identified the writers' nationality correctly, were more successful in answering questions about writers' ideas and positions toward issues. An interesting point was that subjects' identification of the writers' nationality (context) was usually based on content not linguistic cues. In fact, the claim that there is a two-way relation between content and context of a genre is a plausible one.

\section{Structure effect}

In each of the four administered tests, in addition to questions regarding the text content, purpose, and writer's native language, students were asked to write a summary of the text applying the same structure used by the writers. As the students' summaries showed, contrary to the fact that GSPs of the four texts used in reading comprehension tests were similar, their comprehension of these structures was not similar. The scores on each test were divided into two groups of high and low scores- those who got above the average considered as high score and those below it as low score. The number of subjects comprehending the GSP of text number one was $12(44 \%)$ out of 27 (66\% of 11 high scores and $20 \%$ of 16 low scores), text two was $15(55 \%)$ out of 27 (80\% of 18 high scores and $20 \%$ of 9 low scores), text three was $13(48 \%)$ out of 27 (64\% of 14 high scores and 30\% of 13 low scores), and text four was $15(68 \%)$ out of $22(87 \%$ of 8 high scores and $60 \%$ of 14 low scores). Statistical analyses in all the tests except test 4 revealed a correlation between comprehension of text structures (measured by summaries) and overall comprehension of the texts (determined by students' scores on the tests). This indicates that in these three tests, those students who comprehended the text structure properly; that is those who identified the text structure and applied it in their summaries, gained higher scores in the tests. Although in test 4 about $68 \%$ of the subjects comprehended the text structure successfully, no correlation was found.

The reason for lack of correlation in this test is that both high and low score students had a good comprehension of the text structure and the structure comprehension in this test, in contrast to the three previous tests, could not be considered as a discriminating factor between high and low score students.

Based on the results of the Correlation Coefficient, it may be claimed that there is a bidirectional relation between comprehension of content and structure of a text, meaning that each of the content comprehension and structure comprehension reinforces and improves understanding of the other. Here two assumptions can be suggested- first, students' familiarity with the content of a text helps them understand the text structure, and second, students' comprehension of a text structure increases their understanding of the text content. Remembering that all the four texts used in reading comprehension tests had similar structures and considering the fact that students' overall comprehension of the text 4 (a mean of 3.11), in spite of their high percentage of structure comprehension (68\%), was not as good, it seems that the first assumption is more accurate. In this regard, let us borrow Carrell's (1987) idea that when both content and format are factors at play in ESL reading, content is generally more important than form. When both content and form are familiar, the reading is easy; when both are unfamiliar, reading is relatively difficult. When either form or content is unfamiliar, unfamiliar content poses more difficulties for readers than unfamiliar form.

\section{CONCLUSION}

This study proved that subjects' familiarity with content and context of a genre is an important factor in reading comprehension. However, rhetorical form as a significant phenomenon is more important than content in the comprehension of top-level structure of a text and in the comprehension of event sequence and temporal relationship among events. In other words, each component plays a significant but different role in comprehension (Carrell, 1987: 69). The findings are also in agreement with previous research (Carrell 1984, 1987, 1992, and Johnson 1981 and 1982) about the influence of the content and structure familiarity on reading comprehension. The fact that mental processes are dominant is not particular to this genre; the evidence is proved in other genres (Mathiessen, 1998).

\section{REFERENCES}

[1] Ansary, H. (2004). A cross-cultural analysis of English newspapers. The Linguistic List-Dissertation Abstracts.htm.

[2] Ansary, H. \& E. Babaii. (2004). The generic integrity of newspaper editorials: A systemic functional perspective. Asian EFL Journal 6.1, 1-58.

[3] Ghadessy, M. (1993). On the nature of written business communication. In M. Ghadessy (ed.), Register analysis: theory and practice. London: Pinter Publisher, 149-164.

[4] Halliday, M. A. K. (1994). An introduction to functional grammar (2 ${ }^{\text {nd }}$. ed.). London: Edward Arnold.

[5] Halliday, M. A. K. \& R. Hasan (1989). Language, context, and text: Aspects of language in a social-semiotic perspective (2 ${ }^{\text {nd }}$ ed.). Oxford: Oxford University Press.

[6] Henry, A. \& R. Roseberry (1997). An investigation of the functions, strategies, and linguistic features of the introductions and conclusions of essays. System 25.4, 479-495. 
[7] Hodges, B. A. (2006). An SFL analysis of two genres: Press releases and news articles. bama.ua.edu/ bhodges/portfolio/forms/sfl.pdf

[8] Johnson, P. (1981). Effects of reading comprehension of language complexity and cultural background knowledge of a text. TESOL Quarterly 15.1, 70-82.

[9] Johnson, P. (1982). Effects of reading comprehension of building background knowledge. TESOL Quarterly 16.1, 72-85.

[10] Katajamaki, H. \& M. Koskela. (2007). The rhetorical structure of editorials in English, Swedish and Finnish business newspapers. Teoksessa Proceedings of the 5th International Aelfe Conference. Prensas Universitarias de Zaragoza, $215-219$. http://www.nic.fi/ hesuka/katajamakikoskela.pdf

[11] Matthiessen, C. M. I. M. (1998). Exploring transitivity: Case studies. MS. University of Macquarie.

[12] O'Donnell, M. (2006). Editorials vs. front page news: differences in realis and tense across newspaper genres. Proceedings of the 2nd International Contrastive Linguistics Conference, Compostela, Spain, 1-7.

[13] Paltridge, B. (1993). Writing up research: A systemic functional perspective. System 21.2, 175-192.

[14] Toledo, P. F. (2005). Genre analysis and reading of English as a foreign language: Genre schemata beyond text typologies. Pragmatics 37.4, 1059-1079.

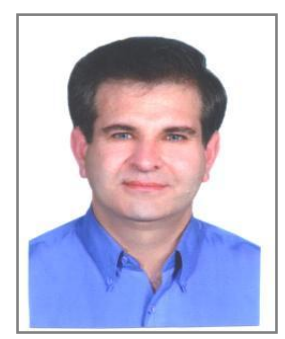

Hossein Shokouhi received his Ph.D. from Australia and is currently an Associate Professor of Linguistics at Shahid Chamran University of Ahvaz, Iran. His interests and teaching areas are discourse, pragmatics, first and second language acquisition, and has published and presented papers widely in these areas.

Dr. Shokouhi has written two books on discourse and psycho-neurolinguistics. He is, at the moment, on the editorial board of a few local and international journals. Dr. Shokouhi has also been a visiting scholar at Potsdam University, Germany and Deusto University, Spain.

Forough Amin holds an M.A. in TEFL from Shahid Chamran University and is currently teaching general and ESP courses at Shahid Chamran University. Her research area includes second language acquisition and genre analysis. 